\title{
REVIEW
}

\section{Meta-analytical approach to explain variation in microbial phosphorus uptake rates in aquatic ecosystems}

\author{
Keith J. Price $^{1, *}$, Hunter J. Carrick ${ }^{1,2}$ \\ ${ }^{1}$ School of Forest Resources, The Pennsylvania State University, University Park, Pennsylvania 16802, USA \\ ${ }^{2}$ Present address: Department of Biology \& Institute for Great Lakes Research, Beaver Island Biological Station, \\ Central Michigan University, Mount Pleasant, Michigan 48859, USA
}

\begin{abstract}
Despite the fact that microbial uptake represents an important transformation of nutrients in aquatic ecosystems, few comprehensive studies have identified key parameters and evaluated their relative importance in explaining variation in uptake rates. Therefore, we performed an assessment of peer-reviewed literature that reported aquatic microbial phosphorus (P) uptake rates. The search yielded 36 different papers which presented results of 102 uptake estimates. We then constructed a meta-analysis to examine the effects of key parameters on uptake. Microbial group (benthic, planktonic), source (culture, wild), and sample time (long, short) were significant parameters in explaining observed variation in published $\mathrm{P}$ uptake rates. Planktonic microbes had higher P uptake rates $\left(65 \mu \mathrm{g} \mathrm{P} \mu \mathrm{g} \mathrm{chl} a^{-1} \mathrm{~d}^{-1}\right)$, compared with benthic $(9 \mu \mathrm{g} \mathrm{P} \mu \mathrm{g}$ chl $a^{-1} \mathrm{~d}^{-1}$ ). Lower affinity for $\mathrm{P}$ by benthic microbes could be attributed to adnate growth forms, which can create boundary layers separating cells from ambient $\mathrm{P}$ and promoting internal $\mathrm{P}$ cycling. Cultured microbes exhibited higher P uptake rates compared with wild samples, although this trend was not significant $(F=2.63, \mathrm{p}=0.108)$, suggesting that cultured microbes in these studies represented reasonable analogues. Shorter sampling times yielded over 3 -fold higher P uptake rates $\left(58 \mu \mathrm{g} \mathrm{P} \mu \mathrm{g} \mathrm{chl} a^{-1} \mathrm{~d}^{-1}\right)$ and appear to represent more accurate estimates of gross uptake. Microbes subject to longer time regimes may be physiologically altered by experimental conditions; estimates might therefore not reflect instantaneous uptake. Our results highlight the influence of ecological variation on $\mathrm{P}$ assimilation and provide criteria for developing a general model to predict observed variation in microbial $\mathrm{P}$ uptake rates.
\end{abstract}

KEY WORDS: Meta-analysis $\cdot$ Benthic $\cdot$ Planktonic $\cdot$ Phosphorus $\cdot$ Ecosystem $\cdot$ Uptake $\cdot$ Mixed model

\section{INTRODUCTION}

Despite the fact that microbial uptake represents an important transformation of nutrients in aquatic ecosystems, few comprehensive studies exist that identify key parameters and evaluate their relative importance in explaining variation in uptake rates. Microbial uptake is a key component contributing to phosphorus (P) cycling models in aquatic environments (Webster et al. 2009). Microbial uptake and other in-stream processes resulted in annual removal of $33 \%$ of the soluble reactive phosphorus (SRP) entering a first-order forested stream (Mulholland 2004). Additionally, periphyton on submerged artificial substrata eliminated $0.83 \mathrm{mg} \mathrm{P} \mathrm{m}^{-2} \mathrm{~d}^{-1}$ from eutrophic lakes (Jöbgen et al. 2004). While benthic 
microbes have a substantial ability to alter P fluxes (Dodds 2003), their uptake velocities have been found to be lower than those of planktonic algae and/or bacteria owing perhaps to boundary-layer constraints (Riber \& Wetzel 1987, Hwang et al. 1998). Conversely, benthic biofilms are typically surrounded by a mucilaginous matrix of extracellular polymeric substances (e.g. polysaccharides; Hoagland et al. 1993) which can aid in sequestration of nutrients from the environment. For instance, polymeric secretions can act as a 'sorptive sponge' binding and concentrating ions in proximity to cells (Decho \& Herndl 1995, Decho 2000), potentially leading to elevated uptake. These varying ideas in the literature suggest that synthesizing kinetic ecological data on these separate but interrelated microbial groups could shed light on $\mathrm{P}$ dynamics in aquatic systems.

While a number of studies have measured $P$ uptake rates for different microbial groups, little has been done to integrate and evaluate uptake rates within and among groups. Bacteria are particularly efficient in removing $\mathrm{P}$ at ambient concentrations owing to their small size and high surface area to volume ratios and have proven superior competitors in terms of uptake kinetics especially at low orthophosphate concentrations (Currie \& Kalff 1984a,b, Rosenberg \& Rmaus 1984). However, phytoplankton display significant P uptake kinetics as well (Tarapchak \& Moll 1990) and can have higher maximum uptake velocities $\left(V_{\max }\right)$ compared with bacteria (e.g. Thingstad et al. 1993). That said, a synthesis of uptake rate values of these microbes could quantify a breadth of rate estimations to determine general differences and lead to a better understanding of variation in reported $\mathrm{P}$ uptake rates. In addition to aforementioned biological differences, previous uptake studies have found that variations in rates may arise due to the effects of experimental and environmental variables (Reynolds \& Kristensen 2008). For example, microbial source (i.e. cultures vs. wild populations) or duration of experimental manipulation can lead to variation which may influence the reported results (Osenberg et al. 1999). This is not ideal because accurate uptake rates are needed for the development of nutrient dynamics (retention) models for aquatic systems (e.g. Marcé \& Armengol 2009). Identifying potential sources of variation in microbial $\mathrm{P}$ uptake studies will promote a more comprehensive understanding and could advance standardization of experimental techniques. Moreover, analysis on the interactive effects of key ecological and experimental variables on $\mathrm{P}$ uptake rates could provide further insight into the interrelatedness of factors affecting uptake measurements, which, to our knowledge, has not been previously attempted.

Meta-analysis is a method for quantitative synthesis and analysis of results and has been used widely in ecology (Hays et al. 2005). Meta-analyses have been effective in providing a quantitative and statistically valid method of comparing findings and exploring variation among multiple ecological studies (Hedges \& Olkin 1985, Arnqvist \& Wooster 1995, Gurevitch \& Hedges 1999, Myers et al. 1999, Francoeur 2001, Stewart 2010). We used a meta-analysis here because it allowed us to summarize and statistically analyze a collection of independent data across a range of research studies (e.g. Hedges \& Olkin 1985, Gurevitch \& Hedges 1999, Osenberg et al. 1999); this approach further allowed us to examine key factors in explaining variation in $\mathrm{P}$ uptake rates. Specifically, we evaluated variation in $\mathrm{P}$ uptake across a series of ecological and experimental parameters (i.e. microbial group, source, experimental sample time, system, region, and non-biological sorption) to explore natural and methodological influences on reported uptake rates.

\section{METHODS}

We performed a comprehensive assessment of the published, peer-reviewed literature to identify experimentally-derived estimates of $\mathrm{P}$ uptake by aquatic microbes. We used mainstream search engines and electronic databases to retrieve data published in the primary scientific literature (i.e. Google Scholar, Biological Abstracts, Web of Science, BioOne, and JSTOR). Additionally, a few journals (e.g. Journal of Phycology) were manually searched from 1970 to 2009. We included in our analysis studies that met the following criteria: (1) uptake was measured for one or both of the specific microbial groups; (2) uptake was derived using P-loss from water or direct microbial P uptake experiments; and (3) uptake values were able to be normalized to common biomass units. While a larger number of uptake measurements have been published, many were excluded due to the absence of chlorophyll $a$ (chl a) data for biomass normalizations (e.g. Rigler 1956). Adherence to these a priori conditions insured that statistical comparisons were made on a common set of standard uptake quantities.

All uptake data were normalized for biomass and expressed in common units, $\mu \mathrm{g} \mathrm{P} \mu \mathrm{g}$ chl $a^{-1} \mathrm{~d}^{-1}$. Some studies that published biomass-normalized uptake estimates were excluded due to expression in incom- 
parable units (e.g. g P cell ${ }^{-1} \mathrm{~h}^{-1}$ ) owing to scale differences (Nan \& Dong 2004). P uptake rate (effect size) extracted from each study was the response variable subjected to further analysis. Chl a values were converted from dry weight (DW) using a literaturederived average carbon (C):chl a ratio of 49.38 for planktonic algae (Bothwell 1985, Riemann et al. 1989, Weisse et al. 1990, Cloern et al. 1995, Coveney \& Wetzel 1995) and 68.22 for benthic algae (de Jonge 1980, Bothwell 1985, Gould \& Gallagher 1990, Romaní \& Sabater 2000) and assuming carbon content of $41.94 \%$ for both microbial groups (Strickland 1965, Mayzaud \& Martin 1975, Härdstedt-Roméo 1982, Andersen \& Hassen 1991, Jørgensen et al. 1991, Klumpp et al. 1992, Anderson 1995, Qin et al. 2007). Chl a values were converted from ash-free dry mass (AFDM) using an AFDM:chl a ratio of 150, which has been used before for periphyton (Warwick 2000); 4 values were converted from these units, all of which were for benthic algae.

We selected key ecological/experimental parameters to test in our analyses, based on primary research. Microbial group was selected to test our a priori hypotheses concerning distinct physiologies between these assemblages (see 'Introduction'). Sample time was added to the model analysis due to its reported influence on uptake kinetics (e.g. Harrison et al. 1989), and source was added to test whether or not cultured microbes adequately represent natural kinetics (Portielje \& Lijklema 1994, Hwang et al. 1998). Factors of 'region' and 'system' were also added to the analysis to test for the influence of geographical and aquatic origin on predicting P uptake, respectively. Finally, testing for abiotic sorption was factored into the analysis because of the varied literature on abiotic processes. For instance, Klotz (1985) found that the contribution of biotic processes to P cycling was minimal in comparison to abiotic processes. However, Khoshmanesh et al. (1999) and Scinto \& Reddy (2003) found biotic processes accounted for a much larger proportion of $\mathrm{P}$ uptake (45\% and $83 \%$, respectively).

Data were then classified into microbial group (benthic and planktonic), source (cultured and wild), sample time (long and short), region (North America and other), system (lentic or lotic), and control for abiotic sorption (yes and no) according to parameters reported. The 'source' parameter was divided into wild samples and culture, which included single species isolates. 'Sample time' was divided into short (0-10 min) and long (>10 min) because of a clear break point in the data set and evidence for the importance of early sampling on the order of minutes or less in kinetic studies (e.g. Goldman et al. 1981, Goldman \& Glibert 1982). Finer resolution among parameters was avoided to prevent rank deficiency in statistical tests. All data were obtained from results reported in the publication text or extracted from published tables and figures. For multiple uptake values reported in a single publication, we used the range for each experiment as stand-alone data entries for the meta-analysis.

Meta-analysis was used to compare the variety of reported uptake rates for all selected ecological/ experimental factors. Some have cautioned against the use of parametric tests for meta-analyses due to variations between values from different experiments and within experiments (Gurevitch \& Hedges 1993, 1999, Stram 1996). The distribution of these data was evaluated using a normal probability plot and an Anderson-Darling normality test statistic. The plot of raw uptake data revealed a strong skew and a heavy right tail, clearly showing that the data are inconsistent with a normal distribution. The data were therefore log transformed $(1+x)$ to base 10 to minimize heteroscedasticity, attain a more normal distribution, and reduce the influence of outliers (Zar 1974). While data transformation was implemented and successful in meeting the homogeneity of variances assumption, the within-study variance (reference parameter) could not be eliminated. Therefore, a mixed-model analysis was used because the heteroscedasticity of the reference parameter violated assumptions of parametric statistical tests (e.g. ANOVA), a common problem in meta-analyses owing to multiple studies with dissimilar variances and sample sizes (Hedges \& Olkin 1985). Gurevitch \& Hedges (1993) and Stram (1996) have proposed the use of mixed models in meta-analysis as a way to combine the advantages of random and fixed effects models as they incorporate a component of betweenstudy variation into the estimates (Gurevitch \& Hedges 1999).

We constructed several mixed models in an effort to determine the best combination of fixed and random effects in determining $P$ uptake rates. A null hypothesis testing approach was used to determine the significance of fixed and random effects in models. An additive approach was followed to the mixed-model fitting, where a series of increasingly complex models were fit and significance of the added effects determined by Bayesian information criterion (BIC) (Kass \& Raftery 1995, Wasserman 2000). BIC is used as criterion in model selection where a smaller BIC indicates better fit between the model and the data; it can measure and compare the degree of support (evidence) in 
the data for multiple competing models. The BIC approach to hypothesis testing may be an improvement over statistical significance testing using p-values because of the ability to test a number of alternative models (Raftery 1995). Further, BIC imposes a higher penalty on the number of parameters (compared to AIC), and therefore leads to the selection of less complicated models (Lin et al. 2009). We used model difference calculations to determine statistical significance of the evidence in favor of one or the other model hypotheses (Neuenschwander et al. 2003). When comparing alternative models, BIC differences of 0 to 2 were interpreted as weak evidence of a given model selection (i.e. impossible to discriminate between models), 6 to 10 showed strong evidence, and $>10$ showed very strong evidence (Raftery 1995).

The 'base' model was simply a null model containing only a fixed intercept used for comparison purposes after addition of terms. Afterwards, a second model with a random intercept (reference) was fit to test the hypothesis that there is significant variation among references in average log(uptake rates). The 'base' model was nested within the second model in that it only differed by a single random effect. In this case, a simple (null) model was compared to a more complex (reference effect) model to see if the added parameter should be used in later analyses. The random intercept (reference) model was a linear mixedmodel fit using restricted maximum likelihood (REML). A fixed grouping (categorical) microbial group term was then added as we proceeded fitting progressively more complex models by adding fixed effect predictor variables. The intent of this additive fitting was to attain the most parsimonious model (most complex, yet simplest). Model assumptions were assessed, specifically normal distribution of residuals, using quantile-quantile (Q-Q) plots of residuals and leverage plots.

Once the best model was derived, those parameters in the model were tested for significance using parametric means (ANOVA). ANOVA (analysis of variance) has been found to be a useful statistical test in meta-analyses (e.g. Brett \& Goldman 1997). We used ANOVA here given that our data met all assumptions for equality of variance (among our groups) and normal, Gaussian data distribution (Gurevitch \& Hedges 1999). For instance, Bartlett's and Levene's tests (equal variances) confirmed homogeneity of variance across all parameters (group, source, and sample time) examined in the meta-analysis ( $p>0.05)$. Mixed-model analyses were performed using $\mathrm{R}$ ( $\mathrm{R}$ Development Core Team 2006). Graphing was carried out using Minitab 16 software. Descriptive statistics and parametric tests were performed using SPSS version 18.0. Mean values and standard error of the mean are reported.

\section{RESULTS}

Our review of the uptake literature identified 102 individual microbial $\mathrm{P}$ uptake experiments recorded in 36 different papers published over a $35 \mathrm{yr}$ period (Table 1). Results from the mixed-model BIC analysis showed that the microbial group model (fixed intercept, random reference, and fixed microbial group) was favored $\left(\Delta_{i}=0.00\right)$, and thus had the greatest degree of support (evidence) in predicting $\mathrm{P}$ uptake (Table 2). The models were ranked in terms of performance in predicting $\mathrm{P}$ uptake rates and further showed that the model containing 'source' was below the suggested maximum for determining strong Bayesian evidence; the model containing the 'sample time' parameter was also smaller than the determination value, and therefore was analyzed further using parametric means (see below). The 'system' parameter was dropped from analysis due to inherent correlation with microbial group. 'Region' and 'abiotic mixed models' were not well supported by the Bayesian evidence.

Of the 102 individual P uptake values reported and analyzed in this meta-analysis, 33 controlled for abiotic sorption, 29 of which were from wild microbial sources. While some experiments controlled for abiotic sorption, values were typically not reported (e.g. Bothwell 1985, Hwang et al. 1998), limiting quantitative analyses. Background phosphorus concentration $\left([\mathrm{P}]\right.$, in $\mu \mathrm{g} \mathrm{l}^{-1}$; range $=<0.001$ to $24.2 \mathrm{mg} \mathrm{l}^{-1}$ ) was extracted from 44 of the 102 experiments and subsequently regressed against corresponding $\mathrm{P}$ uptake values. P uptake (log transformed) showed a significant linear regression against [P] (log transformed) $\left(\mathrm{r}^{2}=0.14, F=7.01, \mathrm{p}=0.011\right)$. Uptake vs. $[\mathrm{P}]$, split by microbial group, showed a slight, negative relationship in benthic experiments and a slight, positive relationship in planktonic experiments; however, neither regression was significant $(p>0.05)$. The biogeochemical conditions in which the studies were conducted varied greatly and prohibited categorization for statistical analysis; experiment locations included the Laurentian Great Lakes, limestone streams, wetlands, and marine areas (e.g. North Sea). Of the 102 individual P uptake estimates, 60\% derived uptake from disappearance of $\mathrm{P}$ from water while $40 \%$ derived from uptake of $\mathrm{P}$ directly into aquatic microbes. Mean P uptake rates were not dif- 
Table 1. Phosphorus uptake rates ( $\mu \mathrm{g} \mathrm{P} \mu \mathrm{g} \mathrm{chl} \mathrm{a}^{-1} \mathrm{~d}^{-1}$ ) measured for 2 microbial functional groups and 5 other experimental variables analyzed in the meta-analysis with associated reference. Original unit abbreviations: dry weight (DW), chlorophyll $a$ ( $\mathrm{chl}$ a), carbon (C), ash-free dry mass (AFDM). Chl a values were converted from DW using an average C:chl a ratio of 49.38 for planktonic algae and 68.22 for benthic algae and assuming a carbon content of $41.94 \%$ for both microbial groups (see 'Methods' for details and references). Chl a values were converted using an AFDM:chl a ratio of 150

\begin{tabular}{|c|c|c|c|c|c|c|c|c|}
\hline $\begin{array}{l}\text { Uptake } \\
\text { values }\end{array}$ & $\begin{array}{l}\text { Original } \\
\text { units }\end{array}$ & $\begin{array}{l}\text { Microbial } \\
\text { group }\end{array}$ & Source & $\begin{array}{c}\text { Sample } \\
\text { time }\end{array}$ & Region & System & $\begin{array}{c}\text { Abiotic } \\
\text { sorption }\end{array}$ & Reference \\
\hline 0.652 & DW & Benthic & Culture & Long & N. America & Lentic & No & Auer \& Canale (1982) \\
\hline 7.32 & DW & Benthic & Culture & Long & N. America & Lentic & No & Auer \& Canale (1982) \\
\hline 1.3 & Chl a & Planktonic & Wild & Short & N. America & Lentic & No & Auer \& Forrer (1998) \\
\hline 11.4 & Chl a & Planktonic & Wild & Short & N. America & Lentic & No & Auer \& Forrer (1998) \\
\hline 0.37 & Chl a & Planktonic & Wild & Short & Other & Lentic & Yes & Berman (1985) \\
\hline 15.03 & Chl a & Planktonic & Wild & Short & Other & Lentic & Yes & Berman (1985) \\
\hline 1.257 & DW & Benthic & Culture & Short & N. America & Lotic & No & Borchardt et al. (1994) \\
\hline 1.847 & DW & Benthic & Culture & Short & N. America & Lotic & No & Borchardt et al. (1994) \\
\hline 2.058 & DW & Benthic & Culture & Short & N. America & Lotic & No & Borchardt et al. (1994) \\
\hline 3.135 & DW & Benthic & Culture & Short & N. America & Lotic & No & Borchardt et al. (1994) \\
\hline 2.64 & Chl a & Benthic & Wild & Short & N. America & Lotic & Yes & Bothwell (1985) \\
\hline 26.4 & Chl a & Benthic & Wild & Short & N. America & Lotic & Yes & Bothwell (1985) \\
\hline 0.576 & Chl a & Benthic & Wild & Short & N. America & Lotic & Yes & Corning et al. (1989) \\
\hline 1.92 & Chl a & Benthic & Wild & Short & N. America & Lotic & Yes & Corning et al. (1989) \\
\hline 0.69 & DW & Planktonic & Wild & Short & N. America & Lentic & No & Cotner \& Wetzel (1992) \\
\hline 10.239 & DW & Planktonic & Wild & Short & N. America & Lentic & No & Cotner \& Wetzel (1992) \\
\hline 0.692 & DW & Planktonic & Wild & Short & N. America & Lentic & No & Cotner \& Wetzel (1992) \\
\hline 5.858 & DW & Planktonic & Wild & Short & N. America & Lentic & No & Cotner \& Wetzel (1992) \\
\hline 5.645 & $\mathrm{Chl} \mathrm{a}$ & Benthic & Wild & Short & N. America & Lotic & No & Davis \& Minshall (1999) \\
\hline 23.285 & Chl a & Benthic & Wild & Short & N. America & Lotic & No & Davis \& Minshall (1999) \\
\hline 0.061 & DW & Benthic & Wild & Long & N. America & Lotic & No & Davis et al. (1990) \\
\hline 0.126 & DW & Benthic & Wild & Long & N. America & Lotic & No & Davis et al. (1990) \\
\hline 59.462 & Chl a & Planktonic & Culture & Short & Other & Lentic & No & Falkner et al. (1984) \\
\hline 62.436 & $\mathrm{Chl} \mathrm{a}$ & Planktonic & Culture & Short & Other & Lentic & No & Falkner et al. (1984) \\
\hline 26.758 & Chl a & Planktonic & Culture & Short & Other & Lentic & No & Falkner et al. (1984) \\
\hline 29.731 & Chl a & Planktonic & Culture & Short & Other & Lentic & No & Falkner et al. (1984) \\
\hline 0.149 & Chl a & Planktonic & Wild & Long & N. America & Lentic & Yes & Harrison et al. (1977) \\
\hline 0.795 & Chl a & Planktonic & Wild & Long & N. America & Lentic & Yes & Harrison et al. (1977) \\
\hline 64.766 & DW & Planktonic & Culture & Long & N. America & Lentic & No & Healey (1973) \\
\hline 0.754 & DW & Benthic & Wild & Long & N. America & Lentic & Yes & Hwang et al. (1998) \\
\hline 30.905 & DW & Benthic & Wild & Long & N. America & Lentic & Yes & Hwang et al. (1998) \\
\hline 0.48 & DW & Benthic & Wild & Long & N. America & Lentic & Yes & Hwang et al. (1998) \\
\hline 177.511 & DW & Benthic & Wild & Long & N. America & Lentic & Yes & Hwang et al. (1998) \\
\hline 0.158 & DW & Planktonic & Wild & Short & N. America & Lentic & Yes & Hwang et al. (1998) \\
\hline 44.95 & DW & Planktonic & Wild & Short & N. America & Lentic & Yes & Hwang et al. (1998) \\
\hline 0.424 & DW & Planktonic & Wild & Short & N. America & Lentic & Yes & Hwang et al. (1998) \\
\hline 612.931 & DW & Planktonic & Wild & Short & N. America & Lentic & Yes & Hwang et al. (1998) \\
\hline 247.572 & $\mathrm{C}$ & Planktonic & Culture & Short & Other & Lentic & No & Istvánovics et al. (2000) \\
\hline 252.786 & $\mathrm{C}$ & Planktonic & Culture & Short & Other & Lentic & No & Istvánovics et al. (2000) \\
\hline 305.998 & $\mathrm{C}$ & Planktonic & Culture & Short & Other & Lentic & No & Istvánovics et al. (2000) \\
\hline 67.196 & $\mathrm{C}$ & Planktonic & Culture & Short & Other & Lentic & No & Istvánovics et al. (2000) \\
\hline 361.343 & $\mathrm{C}$ & Planktonic & Culture & Short & Other & Lentic & No & Istvánovics et al. (2000) \\
\hline 105.95 & $\mathrm{C}$ & Planktonic & Culture & Short & Other & Lentic & No & Istvánovics et al. (2000) \\
\hline 228.847 & C & Planktonic & Culture & Short & Other & Lentic & No & Istvánovics et al. (2000) \\
\hline 0.06 & Chl a & Planktonic & Wild & Long & Other & Lentic & Yes & Karlson (1989) \\
\hline 0.26 & Chl a & Planktonic & Wild & Long & Other & Lentic & Yes & Karlson (1989) \\
\hline 4.602 & $\mathrm{Chl} \mathrm{a}$ & Planktonic & Wild & Short & N. America & Lentic & No & Lean \& White (1983) \\
\hline 64.8 & Chl a & Planktonic & Wild & Short & N. America & Lentic & No & Lean \& White (1983) \\
\hline 0.242 & DW & Benthic & Culture & Long & N. America & Lotic & No & Lohman \& Priscu (1992) \\
\hline 0.648 & DW & Benthic & Culture & Long & N. America & Lotic & No & Lohman \& Priscu (1992) \\
\hline 0.399 & DW & Benthic & Culture & Long & Other & Lentic & No & Nan \& Dong (2004) \\
\hline 14.4 & Chl a & Planktonic & Wild & Long & N. America & Lentic & No & Newman et al. (1994) \\
\hline 57.6 & Chl a & Planktonic & Wild & Long & N. America & Lentic & No & Newman et al. (1994) \\
\hline 62.172 & DW & Planktonic & Culture & Short & Other & Lentic & No & Nyholm (1977) \\
\hline 53.694 & DW & Planktonic & Culture & Short & Other & Lentic & No & Nyholm (1977) \\
\hline
\end{tabular}


Table 1 (continued)

\begin{tabular}{|c|c|c|c|c|c|c|c|c|}
\hline $\begin{array}{l}\text { Uptake } \\
\text { values }\end{array}$ & $\begin{array}{c}\text { Original } \\
\text { units }\end{array}$ & $\begin{array}{l}\text { Microbial } \\
\text { group }\end{array}$ & Source & $\begin{array}{c}\text { Sample } \\
\text { time }\end{array}$ & Region & System & $\begin{array}{c}\text { Abiotic } \\
\text { sorption }\end{array}$ & Reference \\
\hline 14.978 & DW & Planktonic & Culture & Long & Other & Lentic & No & Okada et al. (1982) \\
\hline 20.065 & DW & Planktonic & Culture & Long & Other & Lentic & No & Okada et al. (1982) \\
\hline 0.283 & DW & Planktonic & Culture & Long & Other & Lentic & No & Okada et al. (1982) \\
\hline 0.848 & DW & Planktonic & Culture & Long & Other & Lentic & No & Okada et al. (1982) \\
\hline 33.912 & DW & Planktonic & Culture & Long & Other & Lentic & No & Pauli \& Kaitala (1997) \\
\hline 15.543 & DW & Planktonic & Culture & Long & Other & Lentic & No & Pauli \& Kaitala (1997) \\
\hline 16.391 & DW & Planktonic & Culture & Long & Other & Lentic & No & Pauli \& Kaitala (1997) \\
\hline 10.456 & DW & Planktonic & Culture & Long & Other & Lentic & No & Pauli \& Kaitala (1997) \\
\hline $2.4^{\mathrm{a}}$ & Chl a & Benthic & Wild & Short & N. America & Lotic & Yes & Perrin (1993) \\
\hline $9.6^{\mathrm{a}}$ & Chl a & Benthic & Wild & Short & N. America & Lotic & Yes & Perrin (1993) \\
\hline 106.51 & Chl a & Planktonic & Culture & Short & N. America & Lentic & Yes & Perry (1976) \\
\hline 0.533 & Chl a & Planktonic & Culture & Short & N. America & Lentic & Yes & Perry (1976) \\
\hline 142.04 & Chl a & Planktonic & Culture & Short & N. America & Lentic & Yes & Perry (1976) \\
\hline 122.54 & Chl a & Planktonic & Culture & Short & N. America & Lentic & Yes & Perry (1976) \\
\hline 0.86 & Chl a & Planktonic & Wild & Short & N. America & Lentic & Yes & Perry (1976) \\
\hline 1.1 & Chl a & Planktonic & Wild & Short & N. America & Lentic & Yes & Perry (1976) \\
\hline 6.329 & DW & Benthic & Culture & Long & Other & Lentic & No & Planas et al. (1996) \\
\hline 9.596 & DW & Benthic & Culture & Long & Other & Lentic & No & Planas et al. (1996) \\
\hline 11.513 & DW & Benthic & Culture & Long & Other & Lentic & No & Planas et al. (1996) \\
\hline 11.174 & DW & Benthic & Culture & Long & Other & Lentic & No & Planas et al. (1996) \\
\hline 1.163 & DW & Benthic & Culture & Long & Other & Lentic & No & Planas et al. (1996) \\
\hline 4.536 & Chl a & Benthic & Wild & Long & N. America & Lotic & Yes & K. J. Price \& H. J. Carrick (unpubl.) \\
\hline 1.44 & Chl a & Benthic & Wild & Long & N. America & Lotic & Yes & K. J. Price \& H. J. Carrick (unpubl.) \\
\hline 0.072 & Chl a & Planktonic & Culture & Long & Other & Lentic & No & Prieto et al. (1997) \\
\hline 0.041 & Chl a & Planktonic & Culture & Long & Other & Lentic & No & Prieto et al. (1997) \\
\hline 7.2 & Chl a & Planktonic & Wild & Long & Other & Lentic & No & Riegman \& Mur (1986) \\
\hline 50.4 & Chl a & Planktonic & Wild & Long & Other & Lentic & No & Riegman \& Mur (1986) \\
\hline 136.8 & Chl a & Planktonic & Wild & Long & Other & Lentic & No & Riegman \& Mur (1986) \\
\hline 19.647 & $\mathrm{C}$ & Benthic & Culture & Short & N. America & Lentic & No & Rosemarin (1982) \\
\hline 0.953 & $\mathrm{C}$ & Benthic & Culture & Short & N. America & Lentic & No & Rosemarin (1982) \\
\hline 3.023 & DW & Benthic & Culture & Short & Other & Lentic & No & Runcie et al. (2004) \\
\hline 8.001 & DW & Benthic & Culture & Short & Other & Lentic & No & Runcie et al. (2004) \\
\hline 1.507 & DW & Benthic & Culture & Short & Other & Lentic & No & Runcie et al. (2004) \\
\hline 0.439 & DW & Benthic & Culture & Short & Other & Lentic & No & Runcie et al. (2004) \\
\hline 5.372 & DW & Benthic & Wild & Long & N. America & Lentic & Yes & Scinto \& Reddy (2003) \\
\hline 3.631 & DW & Benthic & Wild & Long & N. America & Lentic & Yes & Scinto \& Reddy (2003) \\
\hline 1.741 & DW & Benthic & Wild & Long & N. America & Lentic & Yes & Scinto \& Reddy (2003) \\
\hline 115.2 & Chl a & Planktonic & Wild & Short & Other & Lentic & Yes & Sorokin \& Dallocchio (2008) \\
\hline 151.2 & Chl $a$ & Planktonic & Wild & Short & Other & Lentic & Yes & Sorokin \& Dallocchio (2008) \\
\hline 0.108 & AFDM & Benthic & Wild & Short & N. America & Lotic & No & Steinman \& Boston (1993) \\
\hline 0.648 & AFDM & Benthic & Wild & Short & N. America & Lotic & No & Steinman \& Boston (1993) \\
\hline 0.054 & AFDM & Benthic & Wild & Short & N. America & Lotic & No & Steinman et al. (1991) \\
\hline 0.216 & AFDM & Benthic & Wild & Short & N. America & Lotic & No & Steinman et al. (1991) \\
\hline 1.406 & DW & Benthic & Wild & Long & N. America & Lentic & No & Steinman et al. (1997) \\
\hline 3.179 & DW & Planktonic & Wild & Short & N. America & Lentic & No & Steinman et al. (1997) \\
\hline 27.554 & DW & Planktonic & Wild & Short & N. America & Lentic & No & Steinman et al. (1997) \\
\hline 31.2 & Chl a & Planktonic & Wild & Long & Other & Lentic & No & Sweerts et al. (1986) \\
\hline
\end{tabular}

ferent between these experiment methods $(F=0.14$, $\mathrm{p}=0.708)$. Relatedly, $63 \%$ of the experiments used radiotracers in estimating $P$ uptake rates. Uptake rates between tracer experiments (mean $=56.3 \mu \mathrm{g} \mathrm{P}$ $\mu \mathrm{g}$ chl $a^{-1} \mathrm{~d}^{-1}$ ) vs. non-tracer experiments (mean= $15.1 \mu \mathrm{g} \mathrm{P} \mu \mathrm{g} \mathrm{chl} a^{-1} \mathrm{~d}^{-1}$ ) were not significantly different $(F=1.92, p=0.169)$. As stated in methods, microbial group data were split into 2 groups to prevent rank deficiency (interaction term with $<1$ observation for every combination of the factor levels) which prevents full matrix calculations and analysis of all interactions in a 3-way ANOVA. Nonetheless, we parsed microbial group data into 3 groups (benthic microbes, planktonic microbes, and bacterioplankton) to estimate the effect size of bacteria on $\mathrm{P}$ uptake. Rank deficiencies were present; we there- 
Table 2. Model selection results for predicting the model probability. $K$ is the number of parameters in the model including an intercept, $\log (L)$ is the $\log$ likelihood value for each model, BIC is the Bayesian Information Criterion, and $\Delta_{i}$ is the difference between the BIC value for each model and the model with the lowest $\mathrm{BIC}\left(\mathrm{BIC}_{i}-\mathrm{BIC}_{\mathrm{min}}\right)$. Models were calculated using $\log _{10}$-transformed $\mathrm{P}$ uptake. The intercept/reference model was used as the reduced 'base' model, and thus is not listed

\begin{tabular}{|lcccc|}
\hline Parameter & $K$ & $\log (L)$ & BIC & $\Delta_{i}$ \\
\hline Microbial group & 4 & -185.8 & 390.17 & $0.00^{*}$ \\
Source & 5 & -183.9 & 391.02 & $0.84^{*}$ \\
Sample time & 6 & -183.2 & 394.22 & $4.04^{*}$ \\
Region & 7 & -183.0 & 398.34 & 8.16 \\
Abiotic sorption & 8 & -182.9 & 402.73 & 12.56 \\
* Parameters preserved for analysis with parametric sta- \\
tistics based on strength of evidence \\
\hline
\end{tabular}

fore analyzed these data using a 1-way ANOVA. No data were available for benthic bacteria, thus limiting our analysis to planktonic bacterial groups. Bacterioplankton had 30 observations in the dataset

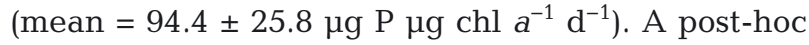
Tukey's HSD test showed that bacterial uptake was significantly different from benthic groups $(\mathrm{p}<0.001)$ but not different from planktonic groups $(p=0.112)$, thus warranting consolidation.

Three-way ANOVA results yielded a significant difference in mean $\mathrm{P}$ uptake rate between microbial groups $(F=21.13, \mathrm{p}<0.001)$ (Table 3$)$. Interactions of microbial group and sample time $(F=4.80, \mathrm{p}=0.031)$ and source and sample time $(F=4.22, \mathrm{p}=0.043)$ were also significant in the analysis. A 3-way interaction of microbial group, source, and sample time $(F=3.68$, p

Table 3. ANOVA results examining differences among predictors of $\log _{10^{-}}$ transformed $\mathrm{P}$ uptake rate $\left(\mu \mathrm{g} \mathrm{P} \mu \mathrm{g} \mathrm{chl} \mathrm{a}^{-1} \mathrm{~d}^{-1}\right)$ : microbial group, source, and sample time. ${ }^{*}$ Mean difference is significant at the $\alpha=0.05$ level

\begin{tabular}{|lccccc|}
\hline Variable & $\begin{array}{c}\text { Type III sum } \\
\text { of squares }\end{array}$ & df & $\begin{array}{c}\text { Mean } \\
\text { square }\end{array}$ & $F$ & $\alpha$ \\
\hline Corrected model & 21.581 & 7 & 3.083 & 7.708 & 0.000 \\
Intercept & 75.866 & 1 & 75.866 & 189.671 & 0.000 \\
Group & 8.450 & 1 & 8.450 & 21.127 & $0.000^{*}$ \\
Source & 1.052 & 1 & 1.052 & 2.631 & 0.108 \\
Sample time & 1.247 & 1 & 1.247 & 3.117 & 0.081 \\
Group $\times$ Source & 1.273 & 1 & 1.273 & 3.182 & 0.078 \\
Group $\times$ Sample time & 1.919 & 1 & 1.919 & 4.799 & $0.031^{*}$ \\
Source $\times$ Sample time & 1.690 & 1 & 1.690 & 4.224 & $0.043^{*}$ \\
Group $\times$ Source $\times$ & 1.471 & 1 & 1.471 & 3.679 & 0.058 \\
$\quad$ Sample time & & & & & \\
Error & 37.599 & 94 & 0.400 & & \\
Total & 152.324 & 102 & & & \\
Corrected total & 59.180 & 101 & & & \\
\hline
\end{tabular}

$=0.058)$ was marginally significant. The mean $\mathrm{P}$ uptake rate for planktonic groups $(65.2 \pm 14.4 \mu \mathrm{g} P \mu \mathrm{g}$ chl $a^{-1} \mathrm{~d}^{-1}$ ) was 7.3 times greater than benthic groups $\left(8.9 \pm 4.1 \mu \mathrm{g} \mathrm{P} \mu \mathrm{g} \mathrm{chl} \mathrm{a}^{-1} \mathrm{~d}^{-1}\right)$ (Table 4, Fig. 1). Experiments using cultured microbes showed higher mean P uptake $\left(52.2 \pm 12.6 \mu \mathrm{g} \mathrm{P} \mu \mathrm{g} \mathrm{chl} \mathrm{a}^{-1} \mathrm{~d}^{-1}\right)$ compared to wild microbes $\left(31.0 \pm 12.2 \mu \mathrm{g} \mathrm{P} \mu \mathrm{g} \mathrm{chl} a^{-1} \mathrm{~d}^{-1}\right)$. Experiments with shorter sample times (0-10 min) had threefold higher mean P uptake rates $(58.0 \pm 14.3 \mu \mathrm{g}$ $\mathrm{P} \mu \mathrm{g}$ chl $\left.a^{-1} \mathrm{~d}^{-1}\right)$ than longer experiments $(17.5 \pm 5.4$ $\mu \mathrm{g} P \mu \mathrm{g} \operatorname{chl} a^{-1} \mathrm{~d}^{-1}$ ).

\section{DISCUSSION}

Bayesian information criterion supported our research hypothesis that microbial group would be the strongest single predictor of $\mathrm{P}$ uptake in the meta-analysis. This finding was further supported in the literature as microbial uptake has been seen to represent an important and significant biological mechanism for P removal in aquatic systems (Confer 1972, McColl 1974, Tarapchak \& Moll 1990, McCormick et al. 2006). Planktonic microbes exhibited higher P uptake rates than benthic microbes, which was in accordance with our hypothesis. Since these 2 distinct communities occupy different niches in aquatic systems (benthic vs. pelagic), there is no reason to believe that their physiological ecology should be similar (Reuter et al. 1986). Additionally, the $\mathrm{P}$ concentration required to saturate growth for benthic microbes is much greater compared to planktonic (Reynolds 2006), likely due to the growth form of benthic assemblages (Hill et al. 2009). Early $P$ cycling research found that most orthophosphate uptake was associated with the smallest aquatic particles (Rigler 1956). Moreover, some planktonic groups have a relatively low P storage capacity (Vadstein et al. 1988), and competition between different aquatic microbial groups for P is a function of both uptake and storage capacity (Kilham 1978).

The lower uptake rates demonstrated by benthic microbes may be attributable to boundary layer formation and internal recycling (Riber \& Wetzel 1987). A diffusive boundary layer has been shown to form around intact microbial biofilms (Jørgensen \& Revsbech 1985). The formation of these physical boundary layers atop 
Table 4. Descriptive statistics for all experimental parameters tested in the meta-analysis of $\mathrm{P}$ uptake rates $\left(\mu \mathrm{g} P \mu \mathrm{g}\right.$ chl $\left.a^{-1} \mathrm{~d}^{-1}\right)$. Missing fields are due to rank deficiency

\begin{tabular}{|c|c|c|c|c|c|c|c|c|}
\hline $\begin{array}{l}\text { Microbial } \\
\text { group }\end{array}$ & Source & $\begin{array}{c}\text { Sample } \\
\text { time }\end{array}$ & Region & System & $\begin{array}{c}\text { Abiotic } \\
\text { sorption }\end{array}$ & $\mathrm{N}$ & Mean & $\begin{array}{l}\text { Standard } \\
\text { deviation }\end{array}$ \\
\hline \multirow[t]{12}{*}{ Benthic } & \multirow[t]{6}{*}{ Culture } & \multirow[t]{3}{*}{ Long } & \multirow[t]{2}{*}{ N. America } & Lentic & No & 2 & 3.99 & 4.72 \\
\hline & & & & Lotic & No & 2 & 0.45 & 0.29 \\
\hline & & & Other & Lentic & No & 6 & 6.70 & 4.94 \\
\hline & & \multirow[t]{3}{*}{ Short } & \multirow[t]{2}{*}{ N. America } & Lentic & No & 2 & 10.30 & 13.22 \\
\hline & & & & Lotic & No & 4 & 2.07 & 0.78 \\
\hline & & & Other & Lentic & No & 4 & 3.24 & 3.34 \\
\hline & \multirow[t]{6}{*}{ Wild } & \multirow[t]{4}{*}{ Long } & \multirow[t]{4}{*}{ N. America } & \multirow[t]{2}{*}{ Lentic } & No & 1 & 1.41 & - \\
\hline & & & & & Yes & 7 & 31.48 & 65.28 \\
\hline & & & & \multirow[t]{2}{*}{ Lotic } & No & 2 & 0.09 & 0.05 \\
\hline & & & & & Yes & 2 & 2.99 & 2.19 \\
\hline & & \multirow[t]{2}{*}{ Short } & \multirow[t]{2}{*}{ N. America } & \multirow[t]{2}{*}{ Lotic } & No & 6 & 4.99 & 9.22 \\
\hline & & & & & Yes & 6 & 7.26 & 9.90 \\
\hline \multirow[t]{11}{*}{ Planktonic } & \multirow[t]{4}{*}{ Culture } & \multirow[t]{2}{*}{ Long } & N. America & Lentic & No & 1 & 64.77 & - \\
\hline & & & Other & Lentic & No & 10 & 11.26 & 11.20 \\
\hline & & \multirow[t]{2}{*}{ Short } & N. America & Lentic & Yes & 4 & 92.91 & 63.27 \\
\hline & & & Other & Lentic & No & 13 & 143.38 & 117.63 \\
\hline & \multirow[t]{7}{*}{ Wild } & \multirow[t]{4}{*}{ Long } & \multirow[t]{2}{*}{ N. America } & \multirow[t]{2}{*}{ Lentic } & No & 2 & 36.00 & 30.55 \\
\hline & & & & & Yes & 2 & 0.47 & 0.46 \\
\hline & & & \multirow[t]{2}{*}{ Other } & \multirow[t]{2}{*}{ Lentic } & No & 4 & 56.40 & 56.44 \\
\hline & & & & & Yes & 2 & 0.16 & 0.14 \\
\hline & & \multirow[t]{3}{*}{ Short } & \multirow[t]{2}{*}{ N. America } & \multirow[t]{2}{*}{ Lentic } & No & 10 & 13.03 & 19.90 \\
\hline & & & & & Yes & 6 & 110.07 & 246.99 \\
\hline & & & Other & Lentic & Yes & 4 & 70.45 & 74.17 \\
\hline
\end{tabular}

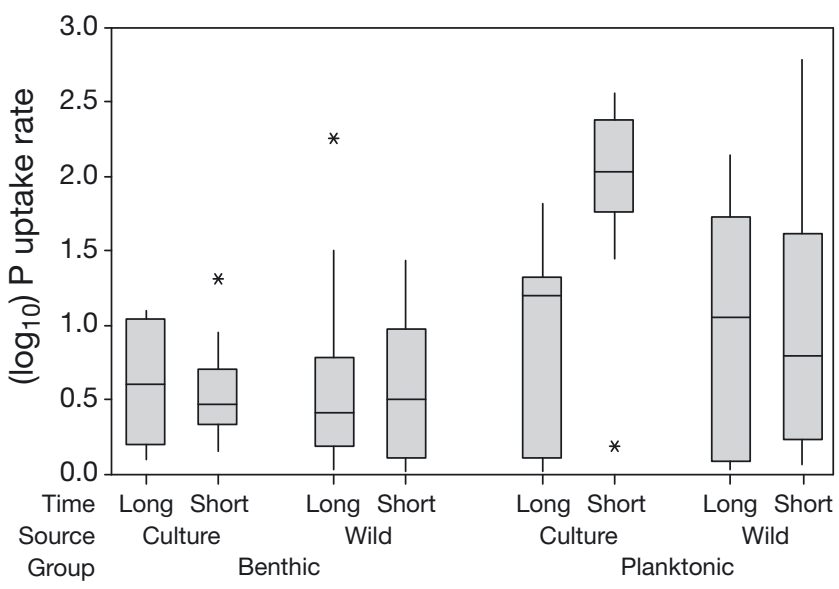

Fig. 1. Boxplot of $\log _{10}$-transformed $\mathrm{P}$ uptake rates for the best predictor parameters determined using mixed modeling: sample time, source, and microbial group. Boxplots show the median value (line) 25 and $75 \%$ quartiles (box), upper and lower limits (whiskers), and outliers (>1.5 times interquartile range; asterisks)

intact benthic films may insulate microbes and inhibit nutrient uptake from the water column into biota within the film (Riber \& Wetzel 1987, Reuter \& Axler 1992, Hwang et al. 1998) thereby reducing the ability of benthic microbes to compete for water column nutrients. Kinetic calculations have shown that internal $\mathrm{P}$ recycling is a more significant source of nutrients than external sources for benthic microbes (Riber \& Wetzel 1987). These results suggest that there is an intrinsic, physical, and resultant chemical conditioning in benthic microbes that favors internal nutrient recycling over ambient water column uptake. Nonetheless, benthic microbes can be competitive with planktonic groups for pelagic $\mathrm{P}$ supply under some circumstances (e.g. Axler \& Reuter 1996). Further, benthic microbes on organic substrates can sequester nutrients associated with the benthos (sediment-water interface) and limit the amount that is released into the water column (Pringle 1990, Hagerthey \& Kerfoot 1998, Woodruff et al. 1999). In this regard, benthic microbes may outcompete planktonic groups for available nutrients (Hansson 1990). That said, the substantial range of $P$ uptake reported in the literature for both benthic and planktonic microbial groups may give some insight into the highly dynamic nature of these assemblages, slowing development of robust dissolved nutrientbiomass models for aquatic systems (Biggs 2000). When splitting the dataset into 3 microbial groups, bacterioplankton showed the greatest uptake rates. This is in accord with past research demonstrating that prokaryotes are capable of rapid and considerable phosphate uptake in aquatic systems, especially during periods of low P levels (Jackim et al. 1977). 
While bacteria may show higher specific orthophosphate uptake rates under P-limiting conditions, phytoplankton in oligotrophic aquatic systems can substitute phospholipids with non-P membrane lipid molecules (Van Mooy et al. 2009), effectively reducing required $\mathrm{P}$ and thus remaining competitive with bacteria. Normalization to chl a would bias uptake rates if bacteria were the principal constituents, but their abundance would be included in carbon, AFDM, and DW estimations (Podgórska et al. 2008, Pusceddu \& Danovaro 2009), all of which were included in this meta-analysis.

The sample time parameter provided moderately strong evidence for predicting P uptake, suggesting it is an important source of variation in experiments (Osenberg et al. 1999). Short sample times averaged over 3 times higher uptake rates than long incubations, a finding accurately supported by other research. For instance, time-course experiments of phosphate uptake in plankton showed that, over a shorter interval (0-60 min) rates were nearly threefold greater than those recorded over the longer interval (60-120 min) (Suttle et al. 1988). Furthermore, the lower P uptake rates found in longer sampling times might suggest a biotic acclimation to nutrients over time and/or oversight of instantaneous/'surge' uptake (Goldman et al. 1981, Harrison et al. 1989); $V_{\max }$ may decrease with increasing incubation time, especially for phosphate (Harrison et al. 1989). Uptake parameters in cells can change rapidly based on the concentration of pulsed nutrients; therefore, longer incubation periods and sampling times might neglect changes in uptake occurring within minutes or seconds (Conway et al. 1976, Goldman \& Glibert 1982, Parslow et al. 1985). Longer incubation times represent uptake that approximates net rates rather than gross rates. For example, incubation times of 30 to 40 min may ignore biotic uptake of remineralized/excreted $\mathrm{P}$ and would result in underestimates of gross uptake (Barlow-Busch et al. 2006). In shorter term experiments, such nutrient recycling is probably minimized and estimates are assumed to represent total (gross) uptake (Steinman \& Mulholland 1996). Phosphate can be released from intercellular P pools, as cytoplasmic $\mathrm{P}$ is readily exchangeable with external $\mathrm{P}$ (Cembella et al. 1984b); P exchange may even exceed net uptake (Lean \& Nalewajko 1976). Further, consumer (e.g. herbivores) excretion could also regenerate bioavailable P (Fisher \& Lean 1992), thereby complicating net uptake estimates. While this would certainly be evident in longer term experiments, short term experiments $(<10 \mathrm{~min})$ would likely not have been influenced by these artifacts to as great a degree and thus may represent membrane transport and initial (gross) uptake rates (see Wheeler et al. 1982).

Cultured microbes showed higher, albeit non-significant, P uptake rates compared to wild microbes. These findings suggest that extrapolation of $P$ uptake values obtained using single species isolates or cultured organisms to natural environments may be reasonable. Though extrapolation of single species $\mathrm{P}$ uptake kinetic estimates to wild communities may be dubious (e.g. Portielje \& Lijklema 1994), present study and others have found that cultured microbes represent a reasonable analogue for wild types. For instance, competitive properties of single isolates of marine microbes in culture have been found to agree with natural conditions (Russell \& Fielding 1974). Further, P limitation in freshwater ecosystems has been demonstrated at several levels of complexity, from algal cultures to whole lakes (Hecky \& Kilham 1988), suggesting some consistency in physiological and environmental responses to phosphorus. However, extrapolation is cautioned against, particularly for benthic groups, as spatial microbial segregation can affect physical transport processes (Portielje \& Lijklema 1994). The significant interaction of group and source/sample time may have been driven by the large values observed for short sampling periods using cultured microbes $\left(\right.$ mean $=83.0 \mu \mathrm{g} \mathrm{P} \mu \mathrm{g} \mathrm{chl} a^{-1}$ $\mathrm{d}^{-1}$ ) and/or competition among wild microbes. Competition for phosphorus among freshwater phytoplankton has been adequately modeled with internal storage capacity and cell size parameters (Smith \& Kalff 1983). In cultured samples and single species isolates, diversity and competition is irrelevant; however, in wild, natural samples there is likely to be strong competition for resources. Competitive responses to nutrient alterations may require some phenotypic modification by microbes (see Demars \& Edwards 2007) and if time-dependent, may explain our significant source/sample interaction. Further, given the controlled conditions in which culture studies are typically performed (e.g. Plato \& Denovan 1974), shorter time sampling periods may be more practicable in these situations than in wild studies. For instance, research with marine phytoplankton culture collections grown to steady state found that the appropriate temporal scale of $\mathrm{NH}_{4}{ }^{+}$uptake may be on the order of seconds (Goldman \& Glibert 1982). However, in a mixed species community (wild) and patchy environs, different microbes must adjust their P uptake system to external P fluctuations (Istvánovics \& Herodek 1995); rapid/short sampling uptake estimates therefore may not be representa- 
tive of an entire mixed assemblage, thereby yielding moderate rates.

The type of uptake experiments being executed was considered in the analysis and showed that rates were similar between $\mathrm{PO}_{4}^{-3}$ disappearance studies and gross/net uptake studies of radiolabeled substrate. While many more experiments derived uptake measurements from disappearance of $\mathrm{P}$ from the water, the actual rates reported were not statistically different. Similarly, Burmaster \& Chisholm (1979), in their comparison of the 2 methods (isotopic tracer and disappearance experiments) for measuring $\mathrm{PO}_{4}{ }^{3-}$ uptake, found they yield comparable results and complement each other in practicality. These findings suggest that between these studies, $\mathrm{P}$ efflux and/or remineralization processes were negligible. Further, our findings may be related to the marginally significant 3 -way interaction found between microbial group, source, and sample time, which indicated unsystematic changes in the data for each microbial group across source and time and suggested that there are additional complexities in interpreting differences between experiment types. Experiments that used tracers (regardless of experiment type) did not show significantly different $\mathrm{P}$ uptake rates from those that did not use tracers, suggesting that both methods are equally sensitive in estimating the magnitude of $\mathrm{P}$ movements.

Despite our care in conducting this meta-analysis, it likely contained biases (Osenberg et al. 1999). There were certain limitations and inherent difficulties in this meta-analysis, including incomplete data reporting, lack of independence among effect-size estimates (although neutralized through mixed modeling), publication bias, and research bias (see Gurevitch \& Hedges 1999). Investigators performing the research may have introduced bias or preference in site/species selection depending on the hypotheses being tested (Dodds \& Welch 2000). In addition, methodologies, investigator rigor, and spatial/temporal scales varied widely. As a result, there remains some uncertainty with reference to microbial differences. Other factors, such as nutrient transport limitation, abiotic uptake, and biphasic uptake can further affect uptake kinetics in both of these microbial organisms (Dodds \& Biggs 2002). With regards to abiotic uptake, as incubation duration decreases, the importance of biological processes relative to physical processes will also decrease (Collos 1983), and passive phenomena (e.g. ion absorption) may be more responsible for measured uptake. We examined the abiotic component of uptake and found it was not a significant predictor of P uptake, suggest- ing that sorptive processes may make up a small fraction of total uptake (e.g. Hwang et al. 1998). This finding is in accord with previous studies showing that biological demand for $\mathrm{P}$ (uptake) exceeds abiotic sorption, which accounts for $<15 \%$ of water column $\mathrm{P}$ removal (Scinto \& Reddy 2003). Nonetheless, the relative importance of adsorptive processes depends on biogeochemistry and varies across stream condition gradients as changes in land-use affect the affinity of abiotic processes for phosphorus (Aldridge et al. 2010). Attention to time-course experiments and the interpretation of results in light of applied experimental conditions (i.e. substrate concentration, incubation, and experiment duration) is important when deducing kinetic rates. Meta-analyses such as these can provide an information platform on which to build a greater understanding of complex environmental systems.

Despite these limitations, which are intrinsic to most meta-analytical approaches, our study revealed important differences in uptake kinetics between aquatic microbes, sample times, and microbial sources. These results indicated that both microbial groups act as important drivers in aquatic P dynamics, although benthic microbes may be less expeditious at removing nutrients from water column sources. The present synthesis and quantitative analysis of $\mathrm{P}$ uptake rates across a range of ecological and experimental parameters has never been previously attempted to our knowledge. The present work is an integrative and important step in realizing the potential of aquatic microbes to function in nutrient transformations and thereby to mitigate nutrient transport to downstream ecosystems (e.g. lakes, oceans). Further, this analysis shows that microbial group, sample time, and microbial source are highly variable; likely dependent on study objectives. Not surprisingly, the range of uptake values spanned over 3 orders of magnitude in accord with previous discussions of variability in $\mathrm{P}$ uptake rates of microbes (e.g. Cembella et al. 1984a). While natural physiology may explain some of this tremendous variation (Auer \& Canale 1982), this meta-analysis sheds light on the potential of different ecological and experimental approaches and parameters to drive such varied rates of uptake. This approach has left the kinetic uptake field with a range of 'quantitative' data that is difficult to interpret and may lead to misleading estimates of true uptake (cf. Strayer 1985).

Microbes represent important $\mathrm{P}$ storage pools in aquatic systems; accurate estimates on the dynamics of nutrient pools can aid in better understanding 
nutrient compartments in flux models. Uptake can control dissolved nutrient concentrations as well as influence regeneration and remineralization, fundamental processes that maintain most primary productivity in aquatic environments (Dodds 1993, Hudson et al. 1999). Additionally, $P$ uptake rates are useful in modeling the distribution of nuisance algal species associated with nutrient perturbations in aquatic systems (e.g. Auer \& Canale 1980). Therefore, there is a need for accurate uptake estimates for models predicting the effects of nutrient management strategies. Differences in experimental conditions may be driving some of the variation in uptake rates observed in this meta-analysis, and, therefore, it may be practical in future experiments to use standardized methodologies so as to create more useful and relatable results (Hein et al. 1995). The results presented here should help in developing aquatic nutrient models by offering insight into some of the ecological factors important in predicting observed variation in microbial $\mathrm{P}$ uptake rates.

Acknowledgements: We thank T. Wagner for valuable assistance with statistical analyses, M. J. McCarthy for constructive comments on a previous version of this manuscript, and J. T. Scannell for assistance with data entry. Funding for this research was provided to H.J.C. by the Pennsylvania Department of Environmental Protection (Grant No. 4100034506). This is contribution \#7 of the CMU Institute for Great Lakes Research.

\section{LITERATURE CITED}

Aldridge KT, Brookes JD, Ganf GG (2010) Changes in abiotic and biotic phosphorus uptake across a gradient of stream condition. River Res Appl 26:636-649

Andersen T, Hassen DO (1991) Carbon, nitrogen, and phosphorus content of freshwater zooplankton. Limnol Oceanogr 36:807-814

Anderson LA (1995) On the hydrogen and oxygen content of marine phytoplankton. Deep-Sea Res 43:1675-1680

Arnqvist G, Wooster D (1995) Meta-analysis: synthesizing research findings in ecology and evolution. Trends Ecol Evol 10:236-240

Auer MT, Canale RP (1980) Phosphorus uptake dynamics as related to mathematical modeling of Cladophora at a site on Lake Huron. J Gt Lakes Res 6:1-7

Auer MT, Canale RP (1982) Ecological studies and mathematical modeling of Cladophora in Lake Huron. 2. Phosphorus uptake kinetics. J Gt Lakes Res 8:84-92

> Auer MT, Forrer BE (1998) Development and parameterization of a kinetic framework for modeling light- and phosphorus-limited phytoplankton growth in Cannonsville Reservoir. Lake Reservior Manage 14:290-300

- Axler RP, Reuter JE (1996) Nitrate uptake by phytoplankton and periphyton: whole-lake enrichments and mesocosm ${ }^{15} \mathrm{~N}$ experiments in an oligotrophic lake. Limnol Oceanogr 41:659-671
Barlow-Busch L, Baulch HM, Taylor WD (2006) Phosphate uptake by seston and epilithon in the Grand River, Southern Ontario. Aquat Sci 68:181-192

Berman T (1985) Uptake of $\left[{ }^{32} \mathrm{P}\right]$ orthophosphate by algae and bacteria in Lake Kinneret. J Plankton Res 7:71-84

Biggs BJF (2000) Eutrophication of streams and rivers: Dissolved nutrient-chlorophyll relationships for benthic algae. J N Am Benthol Soc 19:17-31

> Borchardt MA, Hoffmann JP, Cook PW (1994) Phosphorus uptake kinetics of Spirogyra fluviatilis (Charophyceae) in flowing water. J Phycol 30:403-417

Bothwell ML (1985) Phosphorus limitation of lotic periphyton growth rates: an intersite comparison using continuous-flow troughs (Thompson River system, British Columbia). Limnol Oceanogr 30:527-542

Brett MT, Goldman CR (1997) Consumer versus resource control in freshwater pelagic food webs. Science 275: 384-386

Burmaster DE, Chisholm SW (1979) A comparison of two methods for measuring phosphate uptake by Monochrysis lutheri Droop grown in continuous culture. J Exp Mar Biol Ecol 39:187-202

> Cembella AD, Antia NJ, Harrison PJ (1984a) The utilization of inorganic and organic phosphorous compounds as nutrients by eukaryotic microalgae: a multidisciplinary perspective: Part I. Crit Rev Microbiol 10:317-391

> Cembella AD, Antia NJ, Harrison PJ (1984b) The utilization of inorganic and organic phosphorus compounds as nutrients by eukaryotic microalgae: a multidisciplinary perspective. Part II. Crit Rev Microbiol 11:13-81

Cloern JE, Grenz G, Vidergar-Lucas L (1995) An empirical model of the phytoplankton chlorophyll:carbon ratiothe conversion factor between productivity and growth rate. Limnol Oceanogr 40:1313-1321

Collos Y (1983) Transient situations in nitrate assimilation by marine diatoms. 4. Non-linear phenomena and the estimation of the maximum uptake rate. J Plankton Res 5: 677-691

Confer JL (1972) Interrelations among plankton, attached algae, and the phosphorus cycle in artificial open systems. Ecol Monogr 42:1-23

> Conway HL, Harrison PJ, Davis CO (1976) Marine diatoms grown in chemostats under silicate or ammonium limitation. II. Transient responses of Skeletonema costatum to a single addition of the limiting nutrient. Mar Biol 35:187-199

- Corning K, Duthie H, Paul B (1989) Phosphorus and glucose uptake by seston and epilithon in boreal forest streams. J N Am Benthol Soc 8:123-133

Cotner JB, Wetzel RG (1992) Uptake of dissolved inorganic and organic phosphorus compounds by phytoplankton and bacterioplankton. Limnol Oceanogr 37 : 232-243

> Coveney MF, Wetzel RG (1995) Biomass, production, and specific growth rate of bacterioplankton and coupling to primary production in an oligotrophic lake. Limnol Oceanogr 40:1187-1200

Currie DJ, Kalff J (1984a) A comparison of the abilities of freshwater algae and bacteria to acquire and retain phosphorus. Limnol Oceanogr 29:298-310

> Currie DJ, Kalff J (1984b) The relative importance of bacterioplankton and phytoplankton in phosphorus uptake in freshwater. Limnol Oceanogr 29:311-321

> Davis JC, Minshall GW (1999) Nitrogen and phosphorus uptake in two Idaho (USA) headwater wilderness streams. Oecologia 119:247-255 
Davis LS, Hoffmann JP, Cook PW (1990) Production and nutrient accumulation by periphyton in a wastewater treatment facility. J Phycol 26:617-623

de Jonge VN (1980) Fluctuations in the organic carbon to chlorophyll a ratios for estuarine benthic diatom populations. Mar Ecol Prog Ser 2:345-353

> Decho AW (2000) Microbial biofilms in intertidal systems: an overview. Cont Shelf Res 20:1257-1273

$>$ Decho AW, Herndl GJ (1995) Microbial activities and the transformation of organic matter within mucilaginous material. Sci Total Environ 165:33-42

> Demars B, Edwards A (2007) Tissue nutrient concentrations in freshwater aquatic macrophytes: high inter-taxon differences and low phenotypic response to nutrient supply. Freshw Biol 52:2073-2086

> Dodds WK (1993) What controls levels of dissolved phosphate and ammonium in surface waters? Aquat Sci 55: 132-142

> Dodds WK (2003) The role of periphyton in phosphorus retention in shallow freshwater aquatic systems. J Phycol 39:840-849

> Dodds WK, Biggs BJF (2002) Water velocity attenuation by stream periphyton and macrophytes in relation to growth form and architecture. J N Am Benthol Soc 21:2-15

> Dodds WK, Welch E (2000) Establishing nutrient criteria in streams. J N Am Benthol Soc 19:186-196

Falkner G, Strasser P, Graffius D (1984) Phosphate uptake by blue green algae in vitro and in a lake during an algal bloom: useful application of a force-flow relationship. Hydrobiologia 108:265-271

Fisher TR, Lean DRS (1992) Interpretation of radiophosphate dynamics in lake waters. Can J Fish Aquat Sci 49:252-258

- Francoeur SN (2001) Meta-analysis of lotic nutrient amendment experiments: detecting and quantifying subtle responses. J N Am Benthol Soc 20:358-368

> Goldman JC, Glibert PM (1982) Comparative rapid ammonium uptake by four species of marine phytoplankton. Limnol Oceanogr 27:814-827

Goldman JC, Taylor CD, Glibert PM (1981) Nonlinear timecourse uptake of carbon and ammonium by marine phytoplankton. Mar Ecol Prog Ser 6:137-148

Gould DM, Gallagher ED (1990) Field measurement of specific growth rate, biomass, and primary production of benthic diatoms of Savin Hill Cove, Boston. Limnol Oceanogr 35:1757-1770

Gurevitch J, Hedges LV (1993) Meta-analysis: Combining the results of independent studies in experimental ecology. In: Scheiner SM, Gurevitch J (eds) The design and analysis of ecological experiments. Chapman \& Hall, New York, NY, p 378-398

> Gurevitch J, Hedges LV (1999) Statistical issues in ecological meta-analyses. Ecology 80:1142-1149

$>$ Hagerthey SE, Kerfoot WC (1998) Groundwater flow influences the biomass and nutrient ratios of epibenthic algae in a north temperate seepage lake. Limnol Oceanogr 43: $1227-1242$

Hansson LA (1990) Quantifying the impact of periphytic algae on nutrient availability for phytoplankton. Freshw Biol 24:265-273

> Härdstedt-Roméo M (1982) Some aspects of the chemical composition of plankton from the North-West Mediterranean Sea. Mar Biol 70:229-236

> Harrison WG, Azam F, Renger EH, Eppley RW (1977) Some experiments on phosphate assimilation by coastal marine plankton. Mar Biol 40:9-18
Harrison PJ, Parslow JS, Conway HL (1989) Determination of nutrient uptake kinetic parameters: a comparison of methods. Mar Ecol Prog Ser 52:301-312

Hays GC, Richardson AJ, Robinson C (2005) Climate change and marine plankton. Trends Ecol Evol 20: 337-344

Healey F (1973) Characteristics of phosphorus deficiency in Anabaena. J Phycol 9:383-394

Hecky RE, Kilham P (1988) Nutrient limitation of phytoplankton in freshwater and marine environments: a review of recent evidence on the effects of enrichment. Limnol Oceanogr 33:796-822

Hedges LV, Olkin I (1985) Statistical methods for metaanalysis. Academic Press, Orlando, FL

> Hein M, Folager Pedersen M, Sand-Jensen K (1995) Sizedependent nitrogen uptake in micro- and macroalgae. Mar Ecol Prog Ser 118:247-253

> Hill WR, Fanta SE, Roberts BJ (2009) Quantifying phosphorus and light effects in stream algae. Limnol Oceanogr 54:368-380

Hoagland KD, Rosowski JR, Gretz MR, Roemer SC (1993) Diatom extracellular polymeric substances: function, fine structure, chemistry and physiology. J Phycol 29:537-566

Hudson JJ, Taylor WD, Schindler DW (1999) Planktonic nutrient regeneration and cycling efficiency in temperate lakes. Nature 400:659-661

Hwang SJ, Havens KE, Steinman AD (1998) Phosphorus kinetics of planktonic and benthic assemblages in a shallow subtropical lake. Freshw Biol 40:729-745

> Istvánovics V, Herodek S (1995) Estimation of net uptake and leakage rates of orthophosphate from ${ }^{32} \mathrm{P}$-uptake kinetics by a linear force-flow model. Limnol Oceanogr 40:17-32

Istvánovics V, Shafik H, Présing M, Juhos S (2000) Growth and phosphate uptake kinetics of the cyanobacterium, Cylindrospermopsis raciborskii (Cyanophyceae) in throughflow cultures. Freshw Biol 43:257-275

> Jackim E, Morisson G, Steel R (1977) Effects of environmental factors on radiocadmium uptake by 4 species of marine bivalves. Mar Biol 40:303-308

> Jöbgen AM, Palm A, Melkonian M (2004) Phosphorus removal from eutrophic lakes using periphyton on submerged artificial substrata. Hydrobiologia 528: $123-142$

> Jørgensen BB, Revsbech NP (1985) Diffusive boundary layers and the oxygen uptake of sediments and detritus. Limnol Oceanogr 30:111-122

Jørgensen SE, Nielsen SN, Jørgensen LA (1991) Handbook of ecological parameters and ecotoxicology. Elsevier, Amsterdam

Karlson B (1989) Seasonal phosphate uptake by size-fractionated plankton in the Skagerrak. J Exp Mar Biol Ecol 127:141-154

Kass RE, Raftery AE (1995) Bayes factors. J Am Stat Assoc 90:773-795

> Khoshmanesh A, Hart BT, Duncan A, Beckett R (1999) Biotic uptake and release of phosphorus by a wetland sediment. Environ Technol 29:85-91

Kilham SS (1978) Nutrient kinetics of freshwater planktonic algae using batch and semicontinuous methods. Mitt Int Ver Theor Angew Limnol 21:147-157

Klotz RL (1985) Factors controlling phosphorus limitation in stream sediments. Limnol Oceanogr 30:543-553

Klumpp DW, Salita-Espinosa JS, Fortes MD (1992) The role of epiphytic periphyton and macroinvertebrate grazers 
in the trophic flux of a tropical seagrass community. Aquat Bot 43:327-349

> Lean DR, Nalewajko C (1976) Phosphate exchange and organic phosphorus excretion by freshwater algae. J Fish Res Board Can 33:1312-1323

Lean D, White E (1983) Chemical and radiotracer measurements of phosphorus uptake by lake plankton. Can J Fish Aquat Sci 40:147-155

Lin D, Shkedy Z, Burzykowski T, Aerts M and others (2009) Classification of trends in dose-response microarray experiments using information theory selection methods. Open Appl Informatics J 3:34-43

> Lohman K, Priscu JC (1992) Physiological indicators of nutrient deficiency in Cladophora (Chlorophyta) in the Clark Fork of the Columbia River, Montana. J Phycol 28: 443-448

- Marcé R, Armengol J (2009) Modeling nutrient in-stream processes at the watershed scale using nutrient spiralling metrics. Hydrol Earth Syst Sci 13:953-967

> Mayzaud P, Martin JLM (1975) Some aspects of the biochemical mineral composition of marine plankton. J Exp Mar Biol Ecol 17:297-310

> McColl RHS (1974) Self-purification of small freshwater streams: phosphate, nitrate, and ammonia removal. N Z J Mar Freshw Res 8:375-388

McCormick PV, Shuford RBE III, Chimney MJ (2006) Periphyton as a potential phosphorus sink in the Everglades Nutrient Removal Project. Ecol Eng 27: 279-289

> Mulholland PJ (2004) The importance of in-stream uptake for regulating stream concentrations and outputs of $\mathrm{N}$ and $\mathrm{P}$ from a forested watershed: evidence from longterm chemistry records from Walker Branch Watershed. Biogeochemistry 70:403-426

Myers RA, Bowen KG, Barrowman NJ (1999) The maximum reproductive rate of fish at low population sizes. Can J Fish Aquat Sci 56:2404-2419

> Nan C, Dong S (2004) Comparative studies on phosphorus uptake and growth kinetics of the microalga Tetraselmis subcordiformis and the macroalga Ulva pertusa. J Ocean Univ China 3:56-59

> Neuenschwander S, Brinkhof MWG, Kölliker M, Richner H (2003) Brood size, sibling competition, and the cost of begging in great tits (Parus major). Behav Ecol 14: 457-462

Newman S, Aldridge F, Phlips E, Reddy R (1994) Assessment of phosphorus availability for natural phytoplankton populations from a hypereutrophic lake. Arch Hydrobiol 130:409-427

Nyholm N (1977) Kinetics of phosphate limited algal growth. Biotechnol Bioeng 19:467-492

Okada M, Sudo R, Aiba S (1982) Phosphorus uptake and growth of blue-green alga, Microcystis aeruginosa. Biotechnol Bioeng 24:143-152

Osenberg CW, Sarnelle O, Cooper SD, Holt RD (1999) Resolving ecological questions through meta-analysis: goals, metrics and models. Ecology 80:1105-1117

Parslow JS, Harrison PJ, Thompson PA (1985) Ammonium uptake by phytoplankton cells on a filter: a new high-resolution technique. Mar Ecol Prog Ser 25:121-129

Pauli ASL, Kaitala S (1997) Phosphate uptake kinetics by Acinetobacter isolates. Biotechnol Bioeng 53: 304-309

Perrin CJ (1993) Pilot fertilization of the Nechako River II: a test of nutrient deficiency and periphyton response to nutrient addition. Nechako Fisheries Conservation Program, Technical Report No. RM88-3

Perry MJ (1976) Phosphate utilization by an oceanic diatom in phosphorus-limited chemostat culture and in the oligotrophic waters of the Central North Pacific. Limnol Oceanogr 21:88-107

Planas D, Maberly SC, Parker JE (1996) Phosphorus and nitrogen relationships of Cladophora glomerata in two lake basins of different trophic status. Freshw Biol 35:609-622

> Plato P, Denovan JT (1974) The influence of potassium on the removal of ${ }^{137} \mathrm{Cs}$ by live Chlorella from low level radioactive wastes. Radiat Bot 14:37-41

Podgórska B, Mudryk ZJ, Skórczewski P (2008) Abundance and production of bacteria in a marine beach (Southern Baltic Sea). Pol J Ecol 56:405-411

Portielje R, Lijklema L (1994) Kinetics of luxury uptake of phosphate by algae-dominated benthic communities. Hydrobiologia 275/276:349-358

Prieto B, Pardo M, Garbisu C, Llama M, Serra J (1997) Phosphate uptake by phosphorus-starved cells of the cyanobacterium Phormidium laminosum. World J Microbiol Biotechnol 13:699-705

> Pringle CM (1990) Nutrient spatial heterogeneity: effects on community structure, physiognomy, and diversity of stream algae. Ecology 71:905-920

Pusceddu A, Danovaro R (2009) Exergy, ecosystem functioning and efficiency in a coastal lagoon: the role of auxiliary energy. Estuar Coast Shelf Sci 84:227-236

Qin P, Mayer CM, Schulz KL, Ji X, Ritchie ME (2007) Ecological stoichiometry in benthic food webs: effect of light and nutrients on periphyton food quantity and quality in lakes. Limnol Oceanogr 42:1436-1443

R Development Core Team (2006) R: a language and environment for statistical computing. R Foundation for Statistical Computing, Vienna. www.R-project.org

Raftery AE (1995) Bayesian model selection in social research. In: Marsden PV (ed) Sociological methodology. Blackwell, Cambridge, MA, p 111-163

Reuter JE, Axler RP (1992) Physiological characteristics of inorganic nitrogen uptake by spatially separate algal communities in a nitrogen-deficient lake. Freshw Biol 27: 227-236

Reuter JE, Loeb SL, Goldman CR (1986) Inorganic nitrogen uptake by epilithic periphyton in a N-deficient lake. Limnol Oceanogr 31:149-160

Reynolds CS (2006) Ecology of phytoplankton. Cambridge University Press, Cambridge

Reynolds CK, Kristensen NB (2008) Nitrogen recycling through the gut and nitrogen economy of ruminants: an asynchronous symbiosis. J Anim Sci 86:E293-E305

> Riber HH, Wetzel RG (1987) Boundary layer and internal diffusion effects on phosphorus fluxes in lake periphyton. Limnol Oceanogr 32:1181-1194

Riegman R, Mur L (1986) Phytoplankton growth and phosphate uptake (for P limitation) by natural phytoplankton populations from the Loosdrecht lakes (The Netherlands). Limnol Oceanogr 31:983-988

Riemann B, Simonsen P, Stensgaard J (1989) The carbon and chlorophyll content of phytoplankton from various nutrient regimes. J Plankton Res 11:1037-1045

> Rigler FH (1956) A tracer study of the phosphorus cycle in lake water. Ecology 37:550-562

> Romaní AM, Sabater S (2000) Influence of algal biomass on extracellular enzyme activity in river biofilms. Microb Ecol 40:16-24 
Rosemarin AS (1982) Phosphorus nutrition of two potentially competing filamentous algae, Cladophora glomerata (L.) Kütz. and Stigeoclonium tenue (Agardh) Kütz. from Lake Ontario. J Gt Lakes Res 8:66-72

Rosenberg G, Rmaus J (1984) Uptake of inorganic nitrogen and seaweed surface area: volume ratios. Aquat Bot 19: $65-72$

Runcie J, Ritchie R, Larkum A (2004) Uptake kinetics and assimilation of phosphorus by Catenella nipae and Ulva lactuca can be used to indicate ambient phosphate availability. J Appl Phycol 16:181-194

Russell G, Fielding AH (1974) The competitive properties of marine algae in culture. J Ecol 62:689-698

Scinto LJ, Reddy KR (2003) Biotic and abiotic uptake of phosphorus by periphyton in a subtropical freshwater wetland. Aquat Bot 77:203-222

Smith REH, Kalff J (1983) Competition for phosphorus among co-occurring freshwater phytoplankton. Limnol Oceanogr 28:448-464

Sorokin YI, Dallocchio F (2008) Dynamics of phosphorus in the Venice lagoon during a picocyanobacteria bloom. J Plankton Res 30:1019-1026

Steinman AD, Boston HL (1993) The ecological role of aquatic bryophytes in a woodland stream. J N Am Benthol Soc 12:17-26

Steinman AD, Mulholland PJ (1996) Measurement of phosphorus limitation, uptake, and turnover in stream algae. In: Hauer FR, Lamberti GA (eds) Methods in stream ecology. Academic Press, San Diego, CA, p 161-190

Steinman AD, Mulholland PJ, Kirschtel DB (1991) Interactive effects of nutrient reduction and herbivory on biomass, taxonomic structure, and P uptake in lotic periphyton communities. Can J Fish Aquat Sci 48:1951-1959

Steinman AD, Meeker RH, Rodusky AJ, Davis WP, Hwang SJ (1997) Ecological properties of charophytes in a large, subtropical lake. J N Am Benthol Soc 16:781-793

Stewart G (2010) Meta-analysis in applied ecology. Biol Lett 6:78-81

Stram DO (1996) Meta-analysis of published data using a linear mixed-effects model. Biometrics 52:536-544

Strayer D (1985) The benthic micrometazoans of Mirror Lake, New Hampshire. Arch Hydrobiol (Suppl. 72): 287-426

Strickland JDH (1965) Production of organic matter in the primary stages of the marine food chain. In: Riley JP,
Skirrow G (eds) Chemical oceanography, Vol. 1. Academic Press, London, p 477-610

Suttle CA, Stockner JG, Shortreed KS, Harrison PJ (1988) Time-courses of size-fractionated phosphate uptake: are larger cells better competitors for pulses of phosphate than smaller cells? Oecologia 74:571-576

> Sweerts JPRA, Gons HJ, Rijkeboer M (1986) Phosphate uptake capacity of summer phytoplankton of the Loosdrecht Lakes in relation to phosphorus loading and irradiance. Hydrobiol Bull 20:101-107

Tarapchak SJ, Moll RA (1990) Phosphorus sources for phytoplankton and bacteria in Lake Michigan. J Plankton Res 12:743-758

Thingstad TF, Skjoldal EF, Bohne RA (1993) Phosphorus cycling and algal-bacterial competition in Sandsfjord, western Norway. Mar Ecol Prog Ser 99:239-259

> Vadstein O, Jensen A, Olsen Y, Reinertsen H (1988) Growth and phosphorus status of limnetic phytoplankton and bacteria. Limnol Oceanogr 33:489-503

> Van Mooy BAS, Fredricks HF, Pedler BE, Dyhrman ST and others (2009) Phytoplankton in the ocean use non-phosphorus lipids in response to phosphorus scarcity. Nature 458:69-72

Warwick JJ (2000) Calleguas Creek Data Analysis in Support of TMDL Determination. Report. Prepared for Larry Walker and Associates, Davis, CA

> Wasserman L (2000) Bayesian model selection and model averaging. J Math Psychol 44:92-107

Webster JR, Newbold JD, Thomas SA, Valett HM, Mulholland PJ (2009) Nutrient uptake and mineralization during leaf decay in streams- a model simulation. Int Rev Hydrobiol 94:372-390

> Weisse T, Müller H, Pinto-Coelho RM, Schweizer A, Springman D, Baldringer G (1990) Response of the microbial loop to the phytoplankton spring bloom in a large prealpine lake. Limnol Oceanogr 35:781-794

Wheeler PA, Glibert PM, McCarthy JJ (1982) Ammonium uptake and incorporation by Chesapeake Bay phytoplankton: short term uptake kinetics. Limnol Oceanogr 27:1113-1128

Woodruff SL, House WA, Callow ME, Leadbeater BSC (1999) The effects of biofilms on chemical processes in surficial sediments. Freshw Biol 41:73-89

Zar JH (1974) Biostatistical analysis. Prentice-Hall, Englewood Cliffs, NJ

Submitted: March 9, 2011; Accepted: August 30, 2011

Proofs received from author(s): November 8, 2011
Editorial responsibility: Patricia Glibert, Cambridge, Maryland, USA 